\title{
Electrochemical Capacitance of Cobalt Oxide Nanotubes on Nickel Foam
}

\author{
V. Yagmur, F.E. Atalay, H. Kaya, D. Avcu and E. Aydogmus \\ Inonu University, Science and Art Faculty, Department of Physics, Malatya, 44280, Turkey
}

\begin{abstract}
In this study, densely packed $\mathrm{Co}_{3} \mathrm{O}_{4}$ nanotubes for supercapacitors have been obtained by means of chemically depositing cobalt hydroxide within a porous anodic aluminum oxide and then annealed at $360{ }^{\circ} \mathrm{C}$. The morphological properties obtained $\mathrm{Co}_{3} \mathrm{O}_{4}$ nanotubes were studied by scanning electron microscopy, the chemical composition was determined by examination of the energy dispersive X-ray spectra. Supercapacitor characteristics such as charging/discharging and impedance $(Z)$ characteristics were also examined.
\end{abstract}

DOI: 10.12693/APhysPolA.123.215

PACS: 81.07.De, 82.47.Uv, 88.80.fh

\section{Introduction}

Capacitors, which store the energy within the electrochemical double-layer at electrode-electrolyte interface have been called as supercapacitors, also known as electrochemical double layer capacitors (EDLC) [1,2]. They have attracted much attention as they can serve as high energy and high power storage devices with a long cycle life [1-6]. Recently, there have been many reports about oxide supercapacitors, which possess excellent electrochemical capacitive behavior [1-6]. In the present study, chemically precipitated $\mathrm{Co}_{3} \mathrm{O}_{4}$ nanotubes on $\mathrm{Ni}$ foams were employed as the electro-active materials for the supercapacitor. The highest specific capacitance, $697 \mathrm{~F} / \mathrm{g}$, was observed at constant current discharge with a current density $0.1 \mathrm{~A} / \mathrm{g}$ in $6 \mathrm{M} \mathrm{KOH}$.

\section{Experimental}

$\mathrm{Co}_{3} \mathrm{O}_{4}$ nanotubes were synthesized by mixing $1 \mathrm{M}$ $\mathrm{CoCl}_{2}$ solution and $1 \mathrm{M} \mathrm{NH}_{4} \mathrm{OH}$. A porous anodic aluminum oxide (AAO) membrane with $200 \mathrm{~nm}$ diameter was used as a template. In the growth of $\mathrm{Co}_{3} \mathrm{O}_{4}$ nanotubes arrays, four membranes were vertically dipped into the solution for $96 \mathrm{~h}$ at room temperature. The formed $\mathrm{Co}(\mathrm{OH})_{2} / \mathrm{AAO}$ nanotubes arrays then were dried for $5 \mathrm{~h}$ in an oven at $60^{\circ} \mathrm{C}$. Then they were heated from room temperature to $360^{\circ} \mathrm{C}$ in air at a rate of $2{ }^{\circ} \mathrm{C} / \mathrm{min}$ and maintained for $2 \mathrm{~h}$. This was followed by cooling to room temperature at a rate of $10^{\circ} \mathrm{C} / \mathrm{min}$. Later the samples were kept in $2 \mathrm{M} \mathrm{NaOH}$ until $\mathrm{AAO}$ template was entirely dissolved, then the liberated nanotubes were suspended in ethanol. Subsequently, the $\mathrm{Co}_{3} \mathrm{O}_{4}$ nanotubes $(75 \%)$, acetylene black (20\%) and PTFE (5\%) were grinded and mixed in a $\mathrm{Zr}_{2} \mathrm{O}_{3}$ mortar for $30 \mathrm{~min}$. $3.33 \mathrm{mg}$ of this mixed material was placed on $\mathrm{Ni}$ foam sheet and compressed at a pressure of $10 \mathrm{MPa}$ for $10 \mathrm{~min}$. Ni foam was used to increase the surface area. The pressed material was used as a cathode, with an exposed area of approximately $1 \mathrm{~cm}^{2}$, for the capacitance measurement. A three-electrode cell was used for the electrochemical experiments. The volume of the electrochemical bath was approximately $50 \mathrm{ml}$. $\mathrm{An} \mathrm{Ag} / \mathrm{AgCl}$ electrode with ceramic frit (Bioanalytical Systems BAS, $3 \mathrm{M} \mathrm{NaCl}$, and $-35 \mathrm{mV}$ versus saturated calomel electrode (SCE) at $25^{\circ} \mathrm{C}$ ) was used as the reference electrode. A platinum electrode approximately $1 \mathrm{~cm}^{2}$ was used as an auxiliary electrode. The electrolyte used was $6 \mathrm{M} \mathrm{KOH}$. Cyclic voltammetry (CV) charge-discharge and electrochemical impedance spectroscopy (EIS) measurements were performed using an electrochemical analyzer system, namely an Iviumstat potentiostat/galvanostat. The frequency limits were typically set between $10 \mathrm{mHz}$ and $100 \mathrm{kHz}$. The AC oscillation amplitude was $5 \mathrm{mV}$. The morphology of the nanoarrays was investigated by scanning electron microscopy (SEM; LEO-EVO-40) and transmission electron microscopy (TEM; FEI Tecnai G2 F30). X-ray diffraction measurement was performed on a RigakuRadb diffractometer equipped with $\mathrm{Cu} K_{\alpha}$ radiation.

\section{Results and discussion}

The general morphology of the chemically precipitated, heated and then removed from AAO nanotubes was studied by SEM and TEM. SEM images of the nanotubes are shown in Fig. 1a. The TEM image of single nanotubes removed from AAO is shown in Fig. 1b. It can be seen from the figures that the diameters of the nanotubes are about $170-200 \mathrm{~nm}$ range and the length is up to $2 \mu \mathrm{m}$. Also internal diameter of nanotubes was measured to be $\approx 100 \mathrm{~nm}$.

Figure 1c shows the XRD profile for nanotubes arrays within AAO. The peaks observed at $2 \theta=$ $18.9^{\circ}, 31.16^{\circ}, 36.76^{\circ}, 44.68^{\circ}, 59.24^{\circ}$ and $65.1^{\circ}$ can be indexed as the (111), (220), (311), (400), (422) and (440) reflections of the spinel $\mathrm{Co}_{3} \mathrm{O}_{4}$. The results are in good agreement with the standard spectrum (PDF CARD NO. $65-5745)$. The broad peak around at $30^{\circ}$ arises from sample holder.

Typical CV for vitreous electrodes at $10 \mathrm{mV} / \mathrm{s}$ are shown in Fig. 2a. The redox signal did not occur at the PTFE and acetylene black electrode surface. In addition, there was a weak signal at $\mathrm{Ni}$ foam electrode surface 


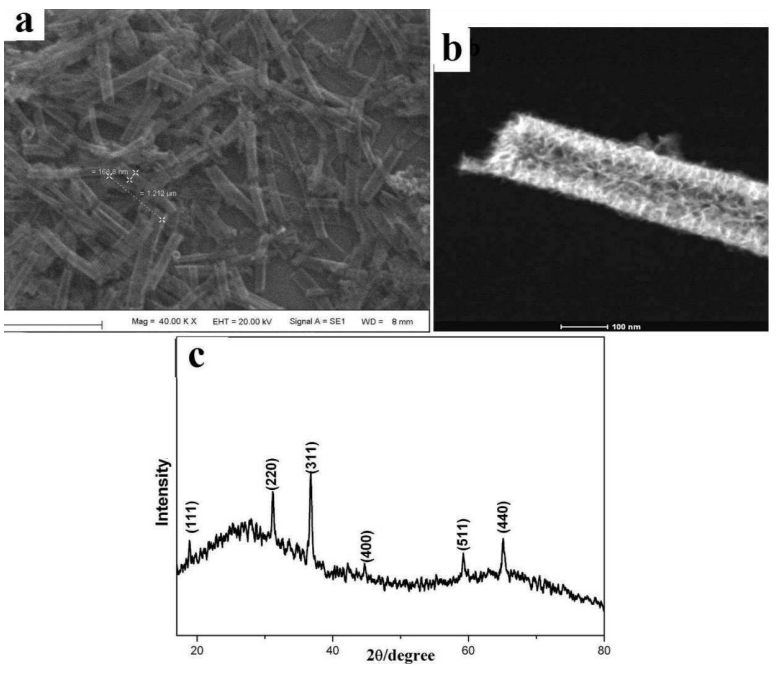

Fig. 1. (a) SEM images of $\mathrm{Co}_{3} \mathrm{O}_{4}$ nanotubes, (b) TEM image of single $\mathrm{Co}_{3} \mathrm{O}_{4}$ nanotubes, (c) XRD spectrum of $\mathrm{Co}_{3} \mathrm{O}_{4}$ nanotubes arrays within AAO.

compared with the $\mathrm{Co}_{3} \mathrm{O}_{4}$ nanotubes, PTFE and acetylene black electrode surface on nickel foam (COPANF). The electrochemical characteristics of the COPANF were studied using cyclic voltammetry with $6.0 \mathrm{M} \mathrm{KOH}$ as the electrolyte, over the voltage range $0-0.5 \mathrm{~V}$ (vs. $\mathrm{Ag} / \mathrm{AgCl}$ ) at various potential scan rates between 1 and $50 \mathrm{mV} / \mathrm{s}$ (Fig. 2b). The CV curves indicate that the electrochemical capacitance of the $\mathrm{Co}_{3} \mathrm{O}_{4}$ samples mainly results from the pseudo-capacitance, which is based on redox mechanism. Also, with increasing scan rate, it was observed that the peak current increases, which suggests good reversibility of fast charge-discharge response. The inset in Fig. 2b shows the effect of scan rate on the cathodic peak currents obtained from CV. The charge-storage mechanism of $\mathrm{Co}_{3} \mathrm{O}_{4}$ is not through a surface redox reaction at the interface but a diffusion controlled reaction.
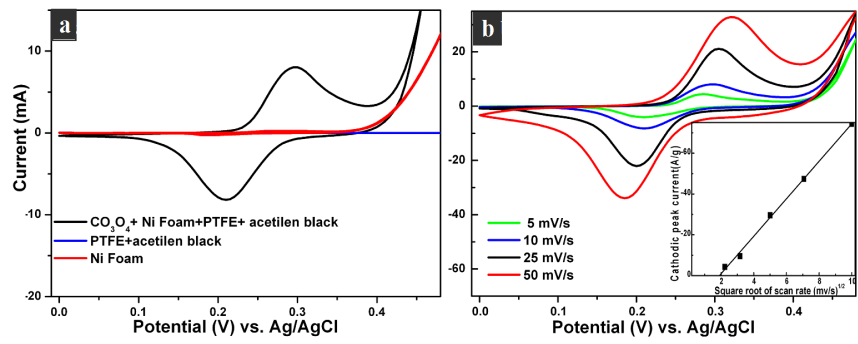

Fig. 2. Cyclic voltammograms of (a) various electrodes at $10 \mathrm{mV} / \mathrm{s}$, (b) COPANF electrodes in $6 \mathrm{M} \mathrm{KOH}$ solution at different scan rates. The inset shows cathodic peak current as a function of the square root of the scan rate.

The inset of Fig. 3a shows first two charge and discharge curves of COPANF electrode materials at $0.1 \mathrm{~A} / \mathrm{g}$ over the operating potential range $0-0.36 \mathrm{~V}$ (vs. $\mathrm{Ag} / \mathrm{AgCl}$ ). The first potential drop arises from the in-
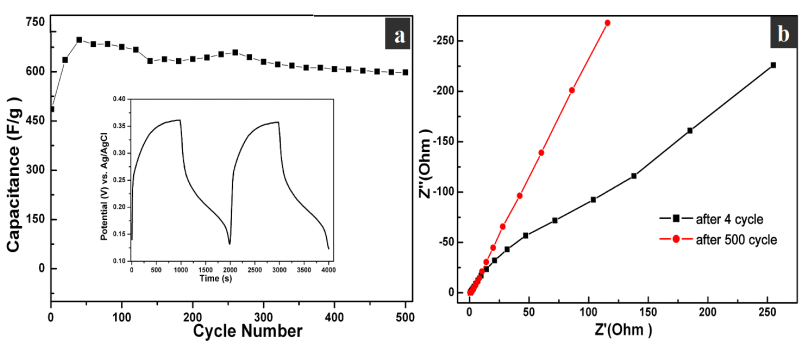

Fig. 3. (a) The specific capacitance as a function of cycle number. The inset shows the first two cyclic chargedischarge curves. (b) Nyquist plots of COPANF sample at $0.1 \mathrm{~A} / \mathrm{g}$ in $6 \mathrm{M} \mathrm{KOH}$ solution.

ternal resistance and the subsequent potential decay indicates a typical pseudocapacitance behavior [3]. The specific capacitance values can be calculated from the following formula:

$$
C_{\mathrm{s}}=\frac{I \Delta t}{m \Delta V},
$$

where $C_{\mathrm{s}}$ is the specific discharge capacitance, $I$ is the discharge current, $\Delta t$ is the discharge time, $\Delta V$ is the potential drop in the discharge progress and $m$ is the active mass of the electrode (including only the mass of the $\mathrm{Co}_{3} \mathrm{O}_{4}$, not the mass of acetylene black, PTFE or Ni foam). The long term galvanostatic cycling stability of COPANF electrode was investigated over 500 cycles (Fig. 3b). The inset shows the first two cyclic chargedischarge curves. The capacitance of COPANF electrode increased gradually during the first 40 cycles and then reached the maximum value of $697 \mathrm{~F} / \mathrm{g}$. Voltammetric and galvanostatic results indicate that the porous structure and large surface area of the $\mathrm{Ni}$ foam and also presence of nanoflakes on the $\mathrm{Co}_{3} \mathrm{O}_{4}$ nanotubes play are mainly responsible for obtaining optimum capacitance values. It exhibits good performance with a high specific capacitance of $598 \mathrm{~F} / \mathrm{g}$ after 500 charge/discharge cycles, corresponding to retention of $86 \%$ of the maximum capacitance. Figure $3 \mathrm{~b}$ displays the Nyquist plots of the AC impedance of the COPANF electrodes $(100 \mathrm{kHz}-10 \mathrm{mHz})$ at open circuit potential. These impedance plots were measured after 4 or 500 continuous charge and discharge cycles. After 500 continuous cycles, $67^{\circ}$ straight lines in the low frequency range demonstrate a good capacitive feature that is the typical characteristic of porous electrodes.

\section{Conclusion}

Chemically precipitated $\mathrm{Co}_{3} \mathrm{O}_{4}$ nanotubes on $\mathrm{Ni}$ foams were employed as the electro-active materials for the supercapacitor. Voltammetric and galvanostatic results indicate that the porous structure and large surface area of the $\mathrm{Ni}$ foam and also presence of nanoflakes on the $\mathrm{Co}_{3} \mathrm{O}_{4}$ nanotubes play are mainly responsible for obtaining optimum capacitance values and long cycle life. The Coulombic efficiency remains above $86 \%$ within 500 cycles. 


\section{Acknowledgments}

This work was supported by Inonu University with project number I.U.A.F-2011/33.

\section{References}

[1] M. Jayalakshmi, K. Balasubramanian, Int. J. Electrochem. Sci. 3, 1196 (2008).

[2] B.E. Conway, Electrochemical Supercapacitors: Scientific Fundamentals and Technological Applications, Kluwer Academic/Plenum Pub., New York 1999.
[3] X. Qing, S, Liu, K. Huang, K. Lv, Y. Yang, Z. Lu, D. Fang, X. Liang, Electrochim. Acta 56, 4985 (2011)

[4] Y. Liu, W. Zhao, X. Zhang, Electrochim. Acta 53, 3296 (2008)

[5] Y. Gao, S. Chen, D. Cao, G. Wang, J. Yin, J. Power Sources 195, 1757 (2010)

[6] Y. Li, K. Huang, S. Liu, Z. Yao, S. Zhuang, J. Solid State Electron. 15, 587 (2011). 